\title{
Direito humano à moradia e a regularização fundiária na Amazônia: limites e possibilidades*
}

\section{Human right to housing and land regularization in the Amazon: limits and possibilities}

\author{
Gabriel Moraes Outeiro* \\ Durbens Martins Nascimento ${ }^{* * *}$
}

\section{Resumo}

Este artigo trata da regularização fundiária na Amazônia como instrumento de garantia do direito humano à moradia. Utiliza, para tanto, a experiência da parceria entre Ministério das Cidades, Universidade Federal do Pará e seis municípios do nordeste paraense na execução do Projeto Moradia Cidadã. A constatação de que o número de moradias irregulares tem crescido exige a adoção de políticas públicas de regularização fundiária para o desenvolvimento urbano, assegurando a inclusão social de todos os cidadãos. Dessa forma, são apresentadas as etapas desse programa de regularização fundiária, revelando limites e possibilidades a serem superados, na medida em que o quadro encontrado traz consigo peculiaridades relacionadas à dinâmica de urbanização amazônica, ao licenciamento urbanístico-ambiental e à gestão municipal do território.

* O artigo foi produto do projeto de pesquisa intitulado "Projeto Moradia Cidadã: Regularização Fundiária e Urbanística em Municípios do Estado do Pará", com base na Lei Federal no 11.952, de 2009, Programa Terra Legal. Trata-se de uma cooperação entre o Ministério das Cidades e a UFPA, cujo objetivo é desenvolver ações de regularização fundiária e urbanística em ocupações existentes sobre terras federais transferidas aos municípios, com base na Lei Federal $n^{\circ} 11.952$, de 2009, que dispõe sobre a regularização fundiária rural e urbana na Amazônia Legal. São trabalhadas áreas nos Municípios de Capitão Poço, Mãe do Rio, Nova Esperança do Piriá, Ipixuna do Pará, Tomé Açú e Concórdia do Pará, contemplando cerca de 14.000 imóveis.

** Doutorando em Desenvolvimento Sustentável do Trópico Úmido pela UFPA. Mestre em Direito pela UFPA. Belém - Pará - Brasil. Email: gmouteiro@gmail.com

*** Doutorado em Ciências: Desenvolvimento Socioambiental (2005) e Mestrado em Planejamento do Desenvolvimento (2000). Cientista Politico. Professor e pesquisador do Programa de Pós Graduação em Desenvolvimento Sustentável do Trópico Úmido - PPGDTU//NAEA/UFPA. Belém - Pará - Brasil. 
Palavras-chave: Projeto Moradia Cidadã. Amazônia. Direito à moradia. Regularização fundiária.

\section{Abstract}

This article deals with land regularization in the Amazon as a instrument of the human right to housing. Uses, for this purpose, the experience of the partnership between the Ministry of Cities, Federal University of Pará and six cities northeastern Pará, in implementing the Projeto Moradia Cidadã. The finding that the number of irregular housing has grown requires the adoption of public policies of land regularization for urban development, ensuring the inclusion of all citizens. Thus are the steps of this land regularization program, to reveal gaps and challenges to be overcome, to the extent that the situation found brings peculiarities, related to the to the dynamics of amazonian urbanization, urban and environmental licensing and municipal land management.

Keywords: Projeto Moradia Cidadã. Amazon. Housing right. Land regularization.

\section{Introdução}

O presente artigo apresenta, de forma problematizada, a regularização fundiária como um instrumento de garantia do direito humano à moradia. Desde a Declaração Universal dos Direitos Humanos, em 1948, a moradia é compreendida como um direito humano. No entanto, apenas posteriormente começou a ser construído um arcabouço jurídico que trouxe densidade a esse direito humano. Nesse passo, uma série de documentos internacionais passou a tratar especificamente do direito à moradia, dimensão da dignidade humana, refletindo no ordenamento jurídico interno, com a farta legislação infraconstitucional existente hoje.

Entretanto, o número de habitações irregulares tem se multiplicado durante as últimas décadas em todas as regiões do Brasil. Estima-se, conforme os dados do Instituto Brasileiro de Geografia e Estatística, obtidos por meio do Censo Demográfico 2010 (IBGE, 2010), que o percentual de domicílios que conta com alguma inadequação habitacional é de cerca da metade do total existente atualmente no Brasil. Mais de 
cinco milhões de moradias dignas precisam ser construídas em todo o país para suprir a demanda atual, de acordo com os dados da Pesquisa Nacional de Amostra por Domicílio, de 2012 (IPEA, 2013, p. 3).

Nesse contexto, com o escopo de enfrentar o alto número de habitações precárias existentes, foi elaborado o Projeto Moradia Cidadã (PMC), um projeto pioneiro, fruto da parceria entre o Ministério das Cidades, a Universidade Federal do Pará (UFPA) e seis municípios do nordeste paraense, com vistas ao fortalecimento institucional municipal para a implementação da Política Nacional de Regularização Fundiária Urbana. Os seis municípios paraenses são: Capitão Poço, Concórdia do Pará, Ipixuna do Pará, Mãe do Rio, Nova Esperança do Piriá e ToméAçu.

Mas, indaga-se, esse projeto preenche os requisitos para garantir uma moradia digna aos ocupantes da área objeto de intervenção? Para responder a essa questão, será apresentado um conceito de moradia digna para lançar luz sobre os componentes do direito à moradia e, dessa forma, mostrar a compatibilidade de políticas de regularização fundiária em ocupações irregulares já consolidadas e com a proteção da moradia. Em seguida, será exposto o PMC, com a análise dos resultados alcançados e, ao final, serão tecidas as sugestões para o aperfeiçoamento desta política.

Como fonte primária, foram analisadas a elaboração e execução do projeto, cujos dados e documentos produzidos foram todos catalogados na Comissão de Regularização Fundiária da UFPA. A hipótese é de que o PMC pode ser um instrumento apto a assegurar o direito humano à moradia da comunidade contemplada pelo projeto.

Pretende-se, a partir do caso concreto, expor soluções generalizáveis para a prática da regularização fundiária na Amazônia, partindo do ponto de vista jurídico, mas estando aberto a dialogar com outras esferas do conhecimento e contribuindo para o entendimento da regularização fundiária como instrumento de inclusão social e de melhoria na qualidade de vida. 


\section{0 direito humano à moradia}

No âmbito interno, o direito à moradia foi incluído no artigo $6^{\circ}$ da Constituição Federal de 1988, por meio da Emenda à Constituição $n^{\circ} 26$, de 2000. A inclusão desse direito no texto constitucional tornou imprescindível a existência de uma arquitetura jurídica protetiva da moradia digna, com a criação de novas leis federais, que mudaram o tratamento legal dispensado para ocupantes em alguma situação de vulnerabilidade.

Por oportuno, traz-se à baila, como mais relevante, a lei de número 10.257/2001, chamada de Estatuto da Cidade. Mas também existem outras, como a Medida Provisória 2.220/2001, que instituiu a concessão de uso especial para fins de moradia (CUEM); e a lei 11.952/2009 prevê mecanismos de regularização fundiária rural e urbana em algumas regiões da Amazônia; a lei 11.977/2009 instituiu o Programa Minha Casa, Minha Vida.

Nessa legislação mais recente, há forte tendência em reconhecer que a ocupação irregular não deve ser tratada pelos mecanismos tradicionais de Direito Civil e de Direito Administrativo, justamente, porque alguns indivíduos podem estar em situação de vulnerabilidade. Essas mudanças já estavam se desenvolvendo anteriormente, em particular, após o advento da Carta Republicana de 88, que trouxe um capítulo específico para tratar da política urbana, nos seus artigos 182 e 183 e, explicitamente, determinou que a propriedade deve cumprir sua função social, em seu art. $5^{\circ}$, inciso XXII. Apenas se quer chamar atenção para o fato de que, além de serem recentes, parte dos instrumentos legais surgiu após o reconhecimento do direito à moradia como um direito constitucional.

A moradia é consagrada como um direito humano, indispensável para a vida digna de qualquer ser humano, desde 1948, ao ser inscrito na Declaração Universal de Direitos Humanos. Essa Declaração tinha por escopo fundar um sistema jurídico internacional centrado no valor fundamental da primazia da dignidade humana. Nesses termos, 
asseguraria a noção do sujeito como um fim em si mesmo, sujeito de direitos pelo simples fato de ser uma pessoa, não podendo ser tratado como um meio ou um objeto. Assim, todo ser humano é titular do direito à moradia, fazendo jus a um espaço no qual possa gozar de uma habitação com qualidade, competindo ao Estado atuar para concretizar esse direito.

Nesse sentido, o homem e a mulher têm o direito, inerente à condição de ser humano, de ocupar um espaço, usualmente, com o intuito de nele permanecer, no qual poderão ser exercidas liberdades fundamentais e estabelecidas relações sociais.

A Declaração de 1948 lista uma série de direitos, divididos em dois grandes grupos, a saber: o dos direitos civis e políticos, e o dos direitos econômicos, sociais e culturais. É no bojo do segundo grupo de direitos humanos, que está localizado o direito à moradia. Ocorre que a previsão do direito à moradia é feita de maneira genérica, no artigo $\mathrm{XXV}^{1}$ desta Declaração. A construção de um arcabouço jurídico envolvendo o direito humano à moradia somente se deu posteriormente.

\subsection{Direito humano à moradia como um direito multidimensional}

A ausência de deveres específicos ou das prestações às quais corresponde o direito à moradia digna na Carta de 88 , permite que se busque em documentos internacionais recentes, pelo menos a título de orientação, a identificação de qual seria o conteúdo desse direito.

Quando se diz recente, é devido ao fato de que apenas há pouco tempo o direito à moradia vem recebendo tratamento legislativo específico em tratados internacionais. A Declaração Universal dos Direitos Humanos previa o direito à intimidade do lar e à habitação desde

"Artigo XXV. 1. Todo ser humano tem direito a um padrão de vida capaz de assegurar-lhe, e a sua família, saúde e bem-estar, inclusive alimentação, vestuário, habitação, cuidados médicos e os serviços sociais indispensáveis, e direito à segurança em caso de desemprego, doença, invalidez, viuvez, velhice ou outros casos de perda dos meios de subsistência em circunstâncias fora de seu controle". 
1948, mas sem imperatividade e coercibilidade que possibilitassem a sua proteção. No mesmo sentido, o Pacto Internacional dos Direitos Econômicos, Sociais e Culturais, em 1966, utilizou, pela primeira vez no plano internacional, a expressão moradia. Em outras palavras, a despeito da moradia digna ser considerada um direito humano desde 1948, o seu tratamento legal permaneceu genérico e abstrato em praticamente todos os instrumentos internacionais ${ }^{2}$.

Com efeito, com base no art. $11^{3}$ do Pacto de 66 , uma resolução foi elaborada pelo Comitê de Direitos Econômicos, Sociais e Culturais das Nações Unidas, denominada Comentário Geral n 4, aprovada na sessão de 13 de dezembro de 1992, que trata dos componentes do direito à moradia. Esse Comentário pode ser identificado como conteúdo do direito à moradia. Nele estão elencados sete elementos essenciais ao direito à moradia adequada, que são: segurança jurídica da posse; disponibilidade de serviços, materiais, equipamentos e infraestrutura; acessibilidade econômica; habitabilidade; acessibilidade para grupos vulneráveis; localização; e adequação cultural.

O Comentário Geral no 4 traz, no mínimo, uma conclusão sobre a maneira como o direito à moradia deve ser compreendido: uma moradia digna não se resume à habitação ou abrigo, abarcando, especialmente, a proteção legal do imóvel, infraestrutura, considerando a localização da residência, em face das relações sociais estabelecidas pelo ocupante.

Ainda que se note alguma preocupação com a qualidade do interior da moradia, como o material usado na construção da habitação

2 Dentre os inúmeros documentos internacionais que protegem a moradia, cabe destacar a Convenção Relativa ao Estatuto dos Refugiados de 1951, a Convenção Americana de Direitos Humanos de 1969, a Declaração sobre Assentamentos Humanos de Vancouver de 1976, a Declaração sobre o Direito ao Desenvolvimento de 1986, e a Convenção sobre os Direitos da Criança de 1989.

3 "Artigo XXI. 1. Os Estados Partes do presente Pacto reconhecem o direito de toda pessoa a um nível de vida adequando para si próprio e sua família, inclusive à alimentação, vestimenta e moradia adequadas, assim como a uma melhoria continua de suas condições de vida. Os Estados Partes tomarão medidas apropriadas para assegurar a consecução desse direito, reconhecendo, nesse sentido, a importância essencial da cooperação internacional fundada no livre consentimento". 
e no adensamento do imóvel, outros fatores têm igual relevância, como a infraestrutura (por exemplo, abastecimento de água por rede geral canalizada; iluminação elétrica; lixo coletado por serviço de limpeza diretamente); a localização que permita aos seus moradores estabelecerem relações sociais (com a comunidade e que possam obter emprego),,o acesso a serviços públicos básicos (como de saúde e de educação) e a proteção jurídica da posse, que não precisa se confundir com a propriedade privada.

Esse último elemento é interessante porque evidencia que, mesmo que a moradia digna deva conferir algum grau de segurança de posse aos ocupantes do imóvel, a lhes garantir proteção jurídica contra despejos forçados e contra outros tipos de interferências indevidas na posse, essa garantia pode se dar com o direito real de uso do solo urbano, ou, residualmente, com um sistema de aluguel social ou outra medida, que não precisa coincidir com a propriedade privada.

Assim, o direito humano à moradia não impede a remoção de pessoas, em especial se a área em que estiver localizada a moradia trouxer riscos aos ocupantes. Nessa situação, exige-se o fornecimento de informação ao morador antes da tomada de decisão e de que o Estado apresente alguma alternativa, como a realocação dos ocupantes para região próxima da área de risco, para que sejam respeitados outros aspectos da moradia digna. Em outras palavras, o direito humano à moradia impõe limites e condições à remoção forçada, mas não elimina essa possibilidade, em casos extremos ou de interesse público.

O direito humano à moradia não conduz, necessariamente, à ilação de que o Estado deve construir parques habitacionais para toda a população. O dever de promover moradias dignas pode dirigir a atuação do Estado para a construção de casas em situações particulares, mas a regra aponta numa outra direção, como a de solucionar a questão dominial dos imóveis e de urbanizar áreas ocupadas.

Há um duplo caráter, em que de um lado há direito individual, pois cada cidadão tem direito a viver com dignidade, sendo titular do direito à moradia, e do outro lado há forte conotação coletiva, pois 
é praticamente impossível individualizar a quantidade exata que cada pessoa se beneficia de alguns serviços públicos. A conjugação desses componentes permite a concretização do direito à moradia e o cumprimento da função social da cidade. Para além da previsão do direito, é preciso executar um planejamento urbano que considere toda a cidade, com áreas urbanas e rurais, leve em conta as particularidades locais e respeite as características da comunidade.

Enquanto dever objetivo, o Poder Público somente tem espaço para definir o caminho, pois pode ser inviável elaborar uma única política habitacional para alcançar todos esses componentes ao mesmo tempo. Existe mais de uma maneira de implementar uma política habitacional coerente, em favor das pessoas que estão em situação de vulnerabilidade. Portanto, para a efetivação do direito à moradia num viés igualitário, deve-se dar prioridade para as camadas da população que estão em alguma condição de hipossuficiência, mas a efetivação desse direito pode se dar por etapas, paulatinamente. Poderia se pensar numa política pública que, no primeiro plano, realize a regularização jurídica do assentamento em que está localizada a comunidade, e, depois, implante, progressivamente, o abastecimento de água por rede geral canalizada, forneça iluminação elétrica, execute o tratamento de resíduos sólidos, dentre outras medidas.

Como se vê, essas são as prestações às quais corresponde o direito à moradia. Logo, a execução de todas essas etapas pode demandar tempo, para que haja elaboração de planos e de metas, definição de custos, realização de acordos de cooperação, dentre outras inúmeras medidas. É possível que haja um longo lapso temporal até que todo o conteúdo do direito à moradia seja concretizado, e um caminho para dotar essa trilha de legitimidade é chamar a própria comunidade para participar desse processo decisório, a fim de selecionar quais as prestações são mais urgentes.

Tendo por fio condutor que mais de cinco milhões de moradias dignas precisam ser construídas em todo o país para suprir a demanda atual (IPEA, 2013, p. 3), a regularização fundiária exsurge como um 
mecanismo eficiente de proteção da moradia digna. Esse raciocínio se deve ao fato de que é difícil, senão improvável, que o Estado consiga suprir todo o déficit habitacional, num espaço curto de tempo, construindo parques habitacionais. Porém, é viável conceber que sejam identificados assentamentos irregulares e, aproveitando a estrutura existente, que sejam sanados os vícios que obstam a fruição da moradia digna, por meio da regularização fundiária com a implementação progressiva do direito à moradia.

\section{A regularização fundiária como instrumento de garantia da moradia digna}

O fenômeno da informalidade urbana vem se manifestando com maior intensidade a partir da metade do século XX no Brasil, pois foi nesse período que ocorreu o crescimento dos centros urbanos (SANTOS; MOTTA, 2001, p. 100-109). Uma das consequências desse processo tem sido o aumento da irregularidade urbana, a ser enfrentado adequadamente.

Genericamente, é correto afirmar que existem dois tipos de irregularidades que afetam os assentamentos humanos, uma de natureza dominial, e outra, urbanístico-ambiental. A irregularidade dominial ocorre quando o possuidor ocupa terra pública ou privada, sem título que Ihe dê garantia jurídica. Os habitantes não são proprietários/ possuidores da área e não têm nenhum documento legal que lhes assegurem permanência no local.

A irregularidade urbanística e ambiental, por sua vez, materializase quando o parcelamento não respeita a legislação urbanística e ambiental e/ou não foi licenciado corretamente. $\mathrm{Na}$ irregularidade urbanística, as etapas previstas na Lei Federal 6.766/79, que dispõe sobre parcelamento do solo urbano, não foram cumpridas, como ocorre com a falta de aprovação municipal de projeto de parcelamento ou pela ausência de registro do loteamento no cartório de imóveis, ou houve afronta à legislação municipal. Também existem casos de ocupações 
de áreas ambientais protegidas, sem nenhum projeto de parcelamento e/ou licenciamento ambiental, e sem obedecer à legislação ambiental vigente.

Diante dessa problemática, a regularização fundiária emerge como uma alternativa de política pública para o tratamento de áreas já ocupadas irregularmente (PRESTES, 2006, p. 42-47). Dentre as diversas diretrizes gerais da política urbana, a Lei Federal 10.257/2001 (Estatuto da Cidade), em seu art. $2^{\circ}$, inciso XIV, dispõe que a regularização fundiária e a urbanização de áreas ocupadas por população de baixa renda será feita mediante o estabelecimento de normas especiais de urbanização, uso e ocupação do solo e edificação, consideradas a situação socioeconômica da população. Dessa forma, é possível atuar nas duas formas de irregularidades existentes.

Como assevera Fernandes (2006, p. 16-17), a regularização fundiária é um processo multidimensional que combina a regularização jurídica da área e dos lotes ocupados, com a regularização urbanística e o fornecimento de infraestrutura básica. No primeiro caso, a política pública restringe-se às ações de cunho jurídico que busquem a legalização da posse ou da propriedade dos imóveis ocupados.

A regularização jurídica pode ser um passo inicial para que, em seguida, proceda-se à dimensão urbanística da regularização fundiária, com a execução de obras públicas capazes de promover melhores condições de vida para as famílias ocupantes de assentamentos irregulares. As medidas podem abarcar a instalação de equipamentos urbanos, como postos de saúde, a construção ou reforma de habitações, o fornecimento de energia elétrica e água tratada, dentre outras.

A regularização urbanística visa adequar a legislação de uso e ocupação do solo para inserir os assentamentos informais no campo da legalidade urbana. Nesse aspecto, é imprescindível, para que a regularização urbanística se aperfeiçoe, que haja coesão na legislação urbanística e que as políticas habitacionais se complementem (LUFT, 2009, p. 59). 
No tocante à definição de quem é o responsável pela regularização fundiária, Luft (2009, p. 53-54) ensina que todos os entes federados têm o dever de executar programas de regularização fundiária, dentro de suas competências constitucionais. Tendo em vista a pluralidade de entes federativos que podem executar programas de regularização fundiária, tem grande relevância o advento da Lei Federal 11.977/2209, que é o primeiro estatuto federal a tratar especificamente de regularização fundiária.

\subsection{Regularização fundiária na Lei Federal 11.977/2009}

A Lei Federal 11.977/2009, mais conhecida por tratar do Programa Minha Casa, Minha Vida, trouxe um capítulo específico sobre regularização fundiária, sistematizando a matéria.

Esse diploma legal, por exemplo, endossa a pluralidade de entes responsáveis pela regularização fundiária, ao dispor que essa política poderá ser promovida por todos os entes federativos. Mas também poderá ser feita por seus beneficiários, individual ou coletivamente, e cooperativas habitacionais, associações de moradores, fundações, organizações sociais, organizações da sociedade civil de interesse público ou outras associações civis que tenham por finalidade atividades nas áreas de desenvolvimento urbano ou regularização fundiária (art. 50, caput e incisos, da Lei Federal 11.977/2009).

Porém, mesmo que a regularização fundiária possa ser promovida por todas essas pessoas, consoante o art. $51, \S 1^{\circ}$ e art. 53, da Lei Federal 11.977/2009, compete ao município definir os requisitos para elaboração do projeto de regularização fundiária, e o projeto de regularização fundiária de interesse social depende da análise e da aprovação municipal.

A regularização fundiária consiste, consoante o art. 46 da Lei Federal 11.977/2009, no conjunto de medidas jurídicas, urbanísticas, ambientais e sociais que visam à regularização de assentamentos irregulares e à titulação de seus ocupantes, de modo a garantir o 
direito social à moradia, o pleno desenvolvimento das funções sociais da propriedade urbana e o direito ao meio ambiente ecologicamente equilibrado. A regularização fundiária é compatível com a moradia digna, estando aberta para a implementação progressiva do direito à moradia.

A Lei Federal 11.977/2009 traz duas espécies de regularização fundiária, a de interesse social e a de interesse específico. Assim, considera-se regularização fundiária de interesse social aquela em que os assentamentos irregulares são ocupados, predominantemente, por população de baixa renda, nos casos em que a área esteja ocupada, de forma mansa e pacífica, há, pelo menos, cinco anos; de imóveis situados em Zonas Especiais de Interesse Social (ZEIS); ou de áreas da União, dos Estados, do Distrito Federal e dos Municípios declaradas de interesse para implantação de projetos de regularização fundiária de interesse social (art. 47, inciso VII, alíneas "a", "b" e "c", da Lei Federal 11.977/2009). A regularização fundiária de interesse específico é aquela em que não está caracterizado o interesse social (art. 47, inciso VIII, da Lei Federal 11.977/2009).

Nesse contexto, os cidadãos devem ser consultados e deve-lhes ser propiciada a participação da formulação, aplicação e avaliação dos planos e programas públicos que são capazes de afetá-los diretamente. Com essa premissa, o indivíduo não recebe apenas os benefícios da execução dos programas públicos, mas deve tomar parte nas decisões políticas vinculantes. A participação da população diretamente afetada por uma política habitacional é um dos meios de considerar os habitantes como sujeitos de direito, em que o indivíduo se torna protagonista no processo de construção dos projetos voltados à garantia de direitos humanos e de empoderamento da população (VÁZQUEZ; DELAPLACE, 2011, p. 45-46).

Nessa concepção, o enfoque da participação popular privilegia a noção de que a comunidade pode e deve influenciar de algum modo nas decisões políticas fundamentais. Na discussão, são relevantes os fatores relacionados às circunstâncias fáticas (econômicas e políticas) da 
sociedade e ao diagnóstico de quais podem ser as melhores estratégias (PRESTES, 2006, p. 37-39).

Trata-se da efetivação de um direito fundamental sobre bases democráticas, em que a imposição de materializar direitos fundamentais é efetivada com o compromisso de cumprir metas, como um desenvolvimento negociado. Há uma obrigação objetiva, implementada segundo critérios que respeitem a vontade da comunidade e as suas necessidades.

A participação popular durante as etapas da concretização do direito à moradia serve como um meio de considerar as pessoas responsáveis e aptas a terem opinião política, como agentes atuantes. É plenamente possível que exsurjam problemas no momento de selecionar os elementos procedimentais, mas algumas noções gerais encontram guarida na Constituição de 88 e na Lei Federal 10.257/2001 (Estatuto da Cidade), em que existem diversos canais abertos para a participação popular, que podem ir de consulta à comunidade até a instituição de conselhos com membros da sociedade civil.

Assim, dentre os inúmeros instrumentos que podem ser usados para garantia do direito à moradia, que respeitem o seu conteúdo e permitam a abertura para canais de participação comunitária, a regularização fundiária representa uma política que consegue absorver tais componentes e pode servir como um mecanismo de promoção da moradia digna.

De acordo com o art. 51 da Lei Federal 11.977/2009, o projeto de regularização fundiária deve definir, no mínimo, as áreas ou lotes a serem regularizados e, se houver necessidade, as edificações que serão relocadas; as vias de circulação existentes ou projetadas e, se possível, as outras áreas destinadas a uso público; as medidas necessárias para a promoção da sustentabilidade urbanística, social e ambiental da área ocupada, incluindo as compensações urbanísticas e ambientais previstas em lei; as condições para promover a segurança da população em situações de risco, considerado o disposto no parágrafo único do 
art. $3^{\circ}$ da Lei $n^{\circ}$ 6.766, de 19 de dezembro de 1979; e, por último, as medidas previstas para adequação da infraestrutura básica.

Portanto, a linha de raciocínio é que a regularização fundiária é um processo pluridimensional, em que diversos atores devem trabalhar em conjunto, ao considerar que a regularização jurídica é insuficiente. Por fim, o mesmo diploma legal mencionado autoriza a execução da regularização fundiária por etapas (art. 51, $\S 3^{\circ}$ ), permitindo que as medidas jurídicas e urbanísticas mencionadas no art. 46 desta lei envolvam a integralidade ou trechos do assentamento irregular objeto de regularização.

Deve-se apenas registrar que, sem ter ocorrido uma sistematização da matéria na Lei Federal 11.977/2009, os demais entes federativos podem legislar sobre o assunto, e ainda estão em vigor outros documentos legais que também dispõem sobre regularização fundiária (AMADEI, 2013, p. 313-314).

Nesses termos, busca-se, a partir de todo o referencial teórico e legal definido, examinar se o Projeto Moradia Cidadã está apto a garantir moradia digna aos ocupantes das áreas dos seis municípios localizados no nordeste paraense.

\section{Projeto moradia cidadã}

Em atendimento ao preceito constitucional da função social da propriedade urbana e ampliação do acesso à terra urbana regularizada, em especial às famílias de menor renda, o Governo Federal promove o Programa Terra Legal, coordenado pelo Ministério de Desenvolvimento Agrário, que tem por escopo transferir a gestão das terras que estão sob tutela do Instituto Nacional de Colonização e Reforma Agrária (INCRA), aos municípios localizados na Amazônia Legal ${ }^{4}$.

No art. $2^{\circ}$, da Lei Complementar 124/2007, estão elencados os Estados-membros que compõe a Amazônia Legal, a saber: os Estados do Acre, Amapá, Amazonas, Mato Grosso, Rondônia, Roraima, Tocantins, Pará e do Maranhão na sua porção a oeste do Meridiano $44^{\circ}$. 
A intenção do Programa Terra Legal, com fulcro na Lei Federal 11.952/2009, é regularizar os assentamentos e ocupações que estão em desacordo com as normas urbanísticas, conferindo prioridade às comunidades locais. Entretanto, para que a comunidade seja devidamente atendida, várias medidas são necessárias e alguns municípios não têm corpo técnico apto para executar tais ações.

Para dar continuidade ao Programa Terra Legal, em dezembro de 2012, o Ministério das Cidades propôs a criação do PMC, em parceria com a UFPA, com vistas ao fortalecimento institucional municipal para a implementação da Política Nacional de Regularização Fundiária Urbana nas terras transferidas aos municípios de Mãe do Rio, Ipixuna do Pará, Tomé-Açu, Concórdia do Pará, Capitão Poço e Nova Esperança do Piriá.

A seleção dos municípios levou em consideração dois critérios, localização e acessibilidade com a cidade de Belém, onde se localiza o Campus Universitário do Guamá da UFPA, visando conferir maior capacidade de mobilidade para atuação das equipes junto aos municípios escolhidos. Os municípios podem ser visualizados na Figura 1.

Figura 1: Mapa de localização dos municípios contemplados pelo PMC.

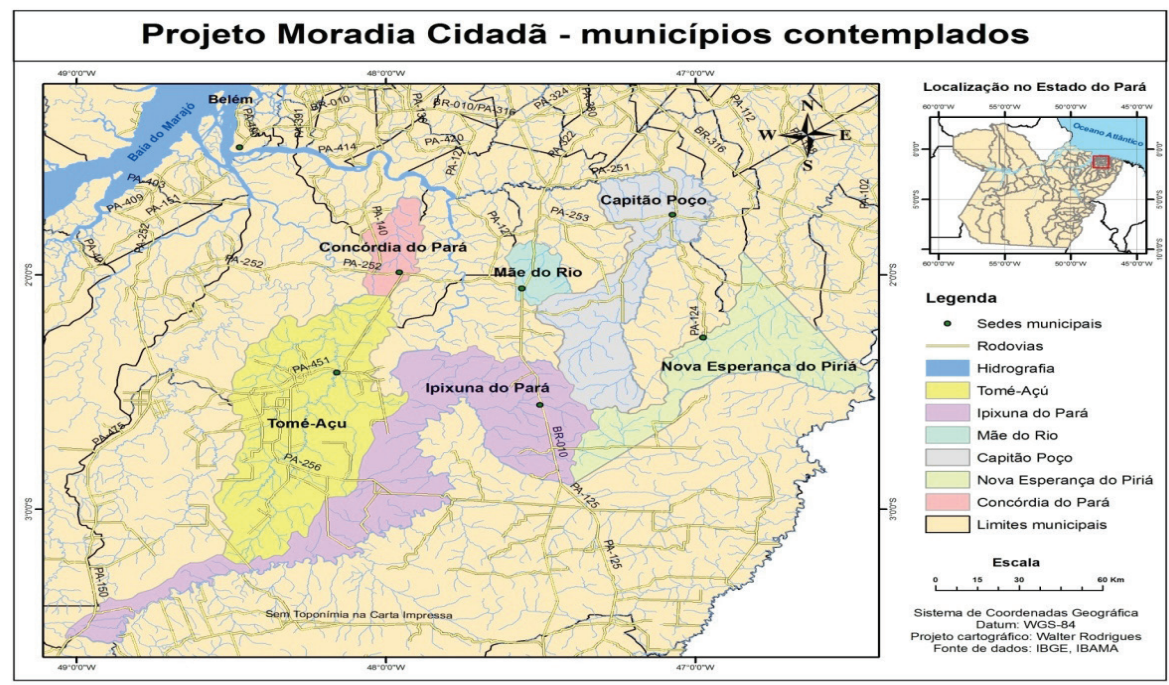

Fonte: IBGE. Elaboração: UFPA, 2013. 
Os municípios de Mãe do Rio, Ipixuna do Pará e Nova Esperança do Piriá receberam áreas que equivalem à quase totalidade da sede municipal. O município de Tomé-Açu recebeu a área onde se localiza o bairro Vila Portelinha, na zona de expansão da cidade. E, por fim, para o município de Concórdia do Pará foram repassadas as áreas de 5 agrovilas, e para Capitão Poço foram doadas 14 agrovilas. No total, foram selecionadas 23 áreas, que podem ser subdivididas em dois grupos: núcleos urbanos consolidados e aglomerações em áreas em transição de uso rural para urbano. A seguir, a Tabela 1, com os quantitativos de glebas e imóveis por localidades e total por municípios.

Tabela 1: Área, lotes e população estimada por área.

\begin{tabular}{lccccc}
\hline Município & Localização & $\begin{array}{c}\text { Área } \\
\mathbf{( H a )}\end{array}$ & $\begin{array}{c}\mathbf{N}^{\circ} \text { de } \\
\text { lotes }\end{array}$ & $\begin{array}{c}\mathbf{N}^{\circ} \text { de } \\
\text { residências }\end{array}$ & $\begin{array}{c}\text { Pop. } \\
\text { Estimada }\end{array}$ \\
\hline Mãe do Rio & Sede & 773 & 10.007 & 7.005 & 33.974 \\
N. Esperança do & Sede & 143.9 & 3.931 & 2.516 & 10.489 \\
Piriá & Sede & 173.3 & 4.896 & 3.037 & 12.148 \\
Ipixuna do Pará & $\begin{array}{c}\text { Sede } \\
\text { Tomé-Açu }\end{array}$ & 73.3 & 1.362 & 776 & 5.135 \\
Concórdia do Pará & 5 Vilas & 13.9 & 128 & 103 & 538 \\
Capítão Poço & 14 Vilas & 273.5 & 2.661 & 1.820 & 7.950 \\
\hline TOTAL & & & $\mathbf{2 2 . 9 8 5}$ & $\mathbf{1 5 . 2 5 7}$ & $\mathbf{7 0 . 2 3 4}$ \\
\hline
\end{tabular}

Fonte: IBGE. Elaboração: UFPA, 2013.

O PMC (UFPA, 2013, p. 8-13) visou realizar ações de regularização fundiária nos assentamentos e lotes existentes nos perímetros urbanos, repassados pelo Programa Terra Legal às administrações municipais, que podem ser condensadas nas seguintes medidas:

1. mobilização dos moradores e de agentes locais, por meio de oficinas técnicas e comunitárias, para atuarem como disseminadores das ações de regularização fundiária;

2. capacitação do corpo técnico municipal para a execução de estudos técnicos, necessários ao processo de regularização fundiária urbana e para a gestão da área; 
3. desenvolvimento de atividades específicas, imprescindíveis para a regularização fundiária, com vistas ao registro de parcelamento do assentamento;

4. realização de estudos urbanísticos, ambientais e topográficos da ocupação existente, subsidiando a elaboração de leis urbanísticas, a aprovação do parcelamento junto ao setor municipal competente e o registro no cartório de imóveis;

5. desenvolvimento de um sistema de informações cadastrais para armazenamento dos dados produzidos pelo projeto de regularização fundiária urbana.

Todas as ações citadas foram realizadas de forma integrada pelas diferentes equipes, que participam do PMC, de maneira que o trabalho foi desenvolvido harmonicamente. Assim, os trabalhos técnicos foram distribuídos para seis grupos diferentes, compostos por técnicos da área administrativa, jurídica, engenharia, informática, urbanística e social.

A equipe administrativa foi responsável pelo desenvolvimento de ações operacionais e técnicas, como a articulação institucional dos membros do município e o apoio ao levantamento de informações. O grupo jurídico examinou a legislação municipal urbanística para verificar sua adequação aos ditames legais da Lei Federal 11.952/2009, apresentou sugestões para a elaboração ou adequação de leis urbanísticas, além de ter analisado o processo de regularização fundiária existente no município.

O desenvolvimento de software, como ferramenta de apoio aos trabalhos de gestão dos dados colhidos pelas outras equipes, ficou a cargo do grupo de informática. A equipe de engenharia realizou o reconhecimento do perímetro de intervenção do projeto, com a identificação da infraestrutura existente, também fez o levantamento topográfico, a confecção da planta de cartografia planialtimétrica cadastral, das plantas de lote e o memorial descritivo. É essa equipe que efetua o cadastro físico-territorial, com a coleta de dados sobre os imóveis da gleba doada. 
O trabalho urbanístico consistiu na análise dos dados cadastrais físicos e imobiliários, da dinâmica de uso e ocupação do solo, das plantas topográficas e no registro fotográfico das unidades. Ou seja, a partir do produto da equipe de engenharia, com a confecção das plantas topográficas e dos lotes, o grupo urbanístico elaborou as plantas de urbanização e de regularização fundiária, consoante a Lei Federal 11.977. Por fim, com a finalidade de assegurar a participação social, a equipe social identificou as organizações sociais, sensibilizou as lideranças comunitárias, organizou treinamentos e oficinas de capacitação para a comunidade e suas lideranças. Quanto às questões relacionadas ao processo de regularização fundiária e os mecanismos de organização e gestão comunitária, é a equipe social que executa o cadastramento social ou socioeconômico, com o levantamento de informações sobre as famílias contempladas no PMC.

A partir das medidas estabelecidas, o PMC visou à regularização de, aproximadamente, 15.000 imóveis residenciais e o cadastro de cerca de 20.000 lotes.

\subsection{Diagnóstico municipal}

Os municípios participantes do PMC se localizam no nordeste paraense e possuem algumas características semelhantes, como o fato de que todos possuem Plano Diretor Municipal ou já têm alguma experiência com a política de regularização fundiária.

Todos os municípios que participam do PMC desenvolvem políticas de regularização fundiária com características semelhantes. Nem todos possuem os mesmos setores ou atuam da mesma forma, mas os procedimentos são similares. Usualmente, todos os municípios atuam na regularização fundiária de seus imóveis na sede municipal, com a atuação do Setor de Tributos e Terras, da Secretária de Administração e Finanças, da Câmara dos Vereadores e do prefeito. Vale ressaltar que as práticas adotadas são utilizadas, predominantemente, em processo de regularização individual do lote, via de regra, parcelado por livre iniciativa do dito proprietário ou posseiro de grandes glebas, em 
sua maioria fazendas, nas quais os lotes titulados são destacados da matrícula mãe da gleba.

No mesmo sentido, é comum que seja utilizada a alienação gratuita do imóvel, com o pagamento, no máximo, das taxas ou de outros tributos relacionados ao trâmite do processo de regularização e ao tamanho do imóvel (mas que não se confundem com o valor do imóvel em si). Em outras palavras, outros instrumentos de regularização fundiária, como CDRU ou CUEM, nos quais a propriedade permanece pública e o direito de uso é transferido aos particulares, não são usados em áreas urbanas.

Notaram-se, no decorrer do Projeto, três questões: a dificuldade em classificar, quanto ao uso do solo, todas as áreas como urbanas, ao mesmo tempo em que não eram claramente rurais; a discussão sobre licenciamentos ambiental e urbanístico, os quais trouxeram certos entraves; e que os municípios paraenses têm dificuldade em executar a gestão do solo.

É importante fazer a observação de que houve discussão sobre a necessidade do licenciamento ambiental em todos os projetos de regularização fundiária, ou se somente seria exigido nos casos em que houvesse impacto ambiental, pois o trabalho seria desenvolvido em áreas com ocupações para fins urbanos consolidadas. Logo, são ocupações que estão consolidadas e cuja regularização fundiária não traria, em análise preliminar, nenhum impacto ambiental. Por outro lado, a existência de APP ou de regularização em áreas de risco tornaria imprescindível a realização do licenciamento ambiental. A Lei Federal 11.977/2009 dispõe, em seu art. 51, caput e parágrafo primeiro, que a regularização fundiária de interesse social depende de aprovação municipal, que corresponde ao licenciamento urbanístico do projeto de regularização, bem como ao licenciamento ambiental, se o município tiver conselho de meio ambiente e órgão ambiental capacitado. Mas não há unanimidade de que esse dispositivo exige, sempre, a realização do licenciamento ambiental, mesmo que não haja impacto ambiental na execução da regularização fundiária. 
Com exceção de Tomé-Açu, nenhum dos municípios possui conselho de meio ambiente e órgão ambiental capacitado. Nesses casos, o licenciamento ficaria a cargo do órgão competente estadual. Ocorre que, quando da visita à Secretaria Estadual de Meio Ambiente, responsável pelo licenciamento ambiental no Estado do Pará, houve certa dificuldade na definição de quais documentos seriam necessários para a realização do procedimento. O impasse decorreu do fato de não ser comum que se obtenha licença ambiental para ações de regularização fundiária urbana.

No outro lado da discussão, estava a questão de que a relação homem-natureza da região amazônica, pelo menos em alguns municípios, traz consigo a particularidade de que, em áreas tidas como urbanas, muitos moradores utilizam o solo para atividades rurais. Seria mais fácil identificá-las como híbridas, do que em uma destas duas categorias.

Portanto, as áreas possuem elementos que as caracterizam como urbanas, seja pelo adensamento, seja pela infraestrutura oferecida pelos entes federados, como energia elétrica, transporte público e rede telefônica. Porém, era comum a utilização do solo para atividades rurais, como agricultura, criação de pequenos animais, além do fato de ser comum que os lotes residenciais tivessem área média superiores a 400 $\mathrm{m}^{2}$, mesmo para a população de baixa renda. Tendo em vista certos aspectos culturais, é interessante que se respeite esse aspecto, embora se mantenha a caracterização do espaço como área urbana.

Por fim, nos municípios nos quais o projeto de regularização estava sendo implementado, era imprescindível que eles executassem a gestão do solo após a finalização do PMC. Foi possível notar que onde a regularização fundiária dos assentamentos estava concentrada nas sedes municipais (como Mãe do Rio e Ipixuna do Pará) houve mais envolvimento no projeto. Entretanto, de forma geral, a gestão do solo e o conjunto de competências constitucionais atribuídas aos municípios ignoram as discrepâncias fáticas existentes entre cada um. Uma capital de um ente federado tem as mesmas competências que um município 
com menos de 20.000 habitantes e com dificuldade em obter recursos financeiros. Com alguns dados apresentados, é possível apresentar os produtos (preliminares) do PMC.

\subsection{Resultados alcançados}

O PMC alcançou diversos resultados positivos e encontrou entraves em todos os municípios. As dificuldades acabaram atrasando o cronograma, inviabilizando a indicação do número de beneficiados diretos, ou até a confecção de todas as plantas de regularização. Todavia, o desenvolvimento do projeto já permite apresentar algumas questões gerais, referentes à regularização fundiária na Amazônia.

Então, como forma de iniciar a regularização fundiária, o primeiro passo foi a mobilização da comunidade diretamente afetada, para que pudesse participar de todas as etapas desenvolvidas pela equipe municipal e pela equipe da UFPA. Dessa maneira, foram realizadas reuniões em cada município para que a população pudesse ser informada sobre o PMC e convidada a integrá-lo.

Num primeiro plano, a primeira reunião buscou familiarizar os moradores com algumas etapas do processo de regularização, nas quais a participação popular se mostra imprescindível. É difícil realizar o cadastro socioeconômico dos ocupantes da área, em que são coletadas informações pessoais e familiares, bem como o cadastro físicoterritorial, no qual são registradas informações referentes ao imóvel, sem a participação da comunidade e sem informá-la anteriormente. Nesses dois cadastros, a aproximação entre a comunidade e os técnicos que efetuam o trabalho de campo auxiliou na coleta de dados. Logo, a conscientização da comunidade sobre o projeto de regularização fundiária foi a primeira medida tomada, tendo precedido a entrada em campo dos técnicos do projeto.

No decorrer do trabalho desenvolvido pelos técnicos da UFPA, os moradores eram convocados para terem conhecimento do andamento do PMC, de acordo com a finalização das etapas anteriores. Nesse 
passo, pode-se afirmar que o PMC atingiu o objetivo de consolidar a participação da população.

Como as áreas foram transferidas como áreas com ocupações para fins urbanos já consolidadas, não foi exigido de nenhum município a existência de ordenamento territorial urbano, que abrangesse as glebas doadas. Assim, três situações foram encontradas durante a execução do PMC:

1. glebas doadas que estavam dentro do perímetro urbano municipal, com a existência de lei municipal que discipline a regularização fundiária (Mãe do Rio, Ipixuna do Pará e Nova Esperança do Piriá);

2. glebas doadas fora do perímetro urbano municipal, ou seja, áreas que fazem parte da zona rural dos municípios, porém, sem a existência de lei municipal que trate de regularização fundiária (Concórdia do Pará e Capitão Poço); e

3. glebas doadas fora do perímetro urbano municipal, com a existência de lei municipal que disponha sobre regularização fundiária (Tomé-Açu).

A lacuna legal motivou a discussão sobre a regularização fundiária dos imóveis, basicamente, por duas razões. O primeiro motivo se refere ao fato de que os Planos Diretores de Concórdia do Pará, de Tomé-Açu e de Capitão Poço definem, em seus mapas, a área do bairro e das vilas alienadas como zonas rurais, a dificultar o enquadramento legal como áreas com ocupações para fins urbanos já consolidadas.

A segunda razão se deve à ausência de legislação municipal urbanística (com exceção do Plano Diretor Municipal, que, entretanto, não contém normas específicas de regularização fundiária) em total conformidade com os encargos presentes na Lei Federal 11.952/2009. Mãe do Rio, Ipixuna do Pará, Nova Esperança do Piriá e Tomé-Açu possuem leis que tratam de regularização fundiária, no entanto, sem a demarcação da região em que seriam aplicáveis, tendo incidência sobre 
a totalidade do município. Já Concórdia do Pará e Capitão Poço não possuem lei que discipline o assunto.

Quanto à Tomé-Açu, Concórdia e Capitão Poço, a ausência de lei municipal ou o enquadramento legal como área urbana não foram considerados óbices à regularização fundiária dos imóveis localizados nas vilas, caracterizadas como zonas rurais. No entanto, foi feita a observação de que seria imprescindível proceder à atualização do perímetro urbano, para abarcar as vilas afetadas pelo PMC, de acordo com ditames previstos no art. 42-B, da Lei Federal 10.257/2001 (Estatuto da Cidade).

Em seguida, no tocante à garantia da segurança jurídica da posse, como um dos componentes do direito à moradia que seria privilegiado pelo PMC, apresentou-se uma cisão entre os moradores que se enquadravam nos termos do inciso I do art. 30, da Lei Federal $11.952 / 2009$ e os demais, em particular para os casos de ocupações mais recentes e que não utilizavam o imóvel para moradia.

Portanto, em todas as vilas ${ }^{5}$ nas quais foi feita a regularização fundiária, foram encontradas três situações:

1. beneficiados com alienação gratuita (que tinham lote com área média menor que $1.000 \mathrm{~m}^{2}$, que não possuíam outro imóvel, com renda familiar inferior à cinco salários mínimos e que ocupavam o imóvel desde fevereiro de 2009);

2. sujeitos à licitação com direito de preferência (porque possuíam imóvel com área média superior a $1.000 \mathrm{~m}^{2}$ ); e

3. os que não se enquadravam em nenhum dos dois casos (principalmente as ocupações posteriores a fevereiro de 2009 ou de moradores que possuíam mais de um imóvel, o que não impediria o município de alienar os imóveis onerosamente, por meio de licitação).

Até a presente data, o cadastro socioeconômico e físico das sedes municipais ainda estava sendo concluído. Portanto, foi nas vilas (de Capitão Poço e Concórdia do Pará) em que o projeto avançou, incluindo com a confecção das plantas de regularização fundiária. 
Nesses termos, o PMC efetuou o cadastro físico-territorial de todos os imóveis e realizou o cadastro socioeconômico de todos os moradores das vilas. No que diz respeito à confecção da planta de parcelamento, oriunda do projeto de regularização, e à instrução processual para a emissão de títulos, focou-se nos moradores que seriam beneficiados com a alienação gratuita, que correspondiam à parte dos lotes. Para os demais casos, o município foi orientado para tomar providências, com a realização da alienação onerosa e com a criação de leis urbanísticas específicas e coerentes entre si, além da adoção de medidas necessárias à melhoria da qualidade de vida da população residente nas glebas doadas.

Então, quanto ao critério de avaliação do $\mathrm{PMC}$, referente à meta de promover segurança jurídica da posse dos ocupantes de áreas públicas, esse objetivo foi alcançado ao beneficiar diretamente parcela da população. Como é possível perceber, a internalização da prática de concretizar a moradia digna pelo Poder Público Municipal foi alcançada parcialmente, pois todos os representantes municipais se interessaram em efetivar a regularização fundiária para beneficiar a todos os ocupantes das áreas, mas nem todos tomaram medidas concretas, ou ao menos iniciaram o debate sobre estas possibilidades.

Tendo em vista a possibilidade de realizar a regularização fundiária por etapas, foi decidido, em parceria com os representantes municipais e com a população, que os imóveis localizados em APP ou área de risco não seriam regularizados nesse primeiro momento. Com relação à discussão sobre a necessidade de efetuar o licenciamento ambiental para regularizar ocupações consolidadas (fora de APP ou de áreas de risco), como precaução, decidiu-se realizar o referido procedimento.

Dessa forma, é possível responder à problemática apresentada na introdução deste trabalho, que indagou se o PMC preenche os requisitos para garantir uma moradia digna aos ocupantes da área objeto de intervenção. No entanto, como é possível notar, após a apresentação de todo o trabalho realizado, a resposta objetiva (se atendeu ou não os 
requisitos de uma moradia digna) pode conduzir a generalizações, que não se coadunam com a realidade.

Em que pese não ser possível apresentar dados objetivos, apenas uma parcela dos ocupantes das áreas públicas (beneficiados com a alienação gratuita) foi contemplada, sem que houvesse uma posição oficial dos municípios, com a apresentação de planos, projetos de leis e programas para os demais. De certo modo, parece faltar interesse político em enfrentar os problemas sociais e/ou consciência do dever municipal de concretizar o direito humano à moradia como um direito multidimensional. Não se deve olvidar que o PMC gerou benefícios à população, em particular aos moradores de baixa renda, e assegurou a participação popular.

Dessa forma, afirma-se que o PMC não preencheu todos os requisitos para garantir uma moradia digna aos ocupantes das áreas objeto de intervenção do Projeto, conquanto ter conseguido melhorar a qualidade de vida de alguns moradores. Ou seja, os benefícios gerados pelo PMC foram limitados.

\section{Conclusão}

Apesar da existência de uma considerável arquitetura jurídica protetiva do direito à moradia e a despeito dos avanços empreendidos, em especial no âmbito federal, permanece certa dificuldade de assegurar moradia digna aos ocupantes de assentamentos irregulares.

Inicialmente, o advento da Lei Federal 11.952/2009 representou um progresso ao possibilitar um tratamento diferenciado para moradores de áreas públicas federais. Ao mesmo tempo, a transferência da responsabilidade para a efetivação da política de regularização fundiária urbana para os municípios daAmazônia Legal também é digna de elogios. O PMC gerou diversos efeitos positivos, como o diálogo constante com a população e a proteção da posse de alguns moradores, além da troca de informações entre os municípios envolvidos, a UFPA e o Ministério das Cidades. 
Por isso, no tocante à hipótese apresentada na parte introdutória deste artigo, deve-se rejeitá-la parcialmente, pois, de modo semelhante ao momento em que se respondeu à problemática apresentada, o PMC gerou benefícios, todavia, seus efeitos foram limitados.

É necessário repensar a obrigatoriedade do licenciamento ambiental e, caso seja mantida, é imprescindível capacitar os órgãos competentes para lidar com a temática. Ao passo que a relação entre o homem-natureza é peculiar em alguns locais, nos quais mesmo que a área seja urbana, o uso do solo tem natureza mista. Aqualidade de vida e o desenvolvimento socioeconômico dos moradores do nordeste paraense dependem da conformação de espaços mais dignos e a produção de um planejamento que consiga abranger a complementaridade entre as atividades urbanas e rurais é indispensável para mudar a realidade municipal.

É preciso ousadia por parte dos representantes políticos municipais para enfrentar os problemas sociais encontrados na cidade e melhorar a gestão do seu próprio território.

\section{Referências}

AMADEI, Vicente de Abreu. Regularização de terras da União. In: NALINI, José Renato; LEVY, Wilson. Regularização fundiária. Rio de Janeiro: Forense, 2013. p. 306-327.

DIAS, Daniella Maria dos Santos. Planejamento e desenvolvimento urbano no sistema jurídico brasileiro: óbices e desafios. Curitiba: Juruá, 2012.

FERNANDES, Edésio. A nova ordem jurídico-urbanística no Brasil. In: ALFONSIN, Betânia; FERNANDES, Edésio (Org.). Direito Urbanístico: estudos brasileiros e internacionais. Belo Horizonte: Del Rey, 2006. p. 3-23. 
INSTITUTO BRASILEIRO DE GEOGRAFIA E ESTATÍSTICA (IBGE). Censo Demográfico 2010. Disponível em: <http://www.censo2010. ibge.gov.br/>. Acesso em: 10 nov. 2013.

INSTITUTO DE PESQUISA ECONÔMICA APLICADA (IPEA).

Estimativas do Déficit Habitacional Brasileiro (PNAD 2007-2012). Brasília: Secretaria de Assuntos Estratégicos da Presidência da República, 2013.

LUFT, Rosangela Marina. Regularização fundiária: superação de mitos e assimilação de premissas. Revista Magister de Direito Ambiental e Urbanístico, Porto Alegre, v. 25, p. 48-67, ago./set. 2009.

PRESTES, Vanêsca Buzelato. Municípios e meio ambiente: a necessidade de uma gestão urbano-ambiental. In: (Org.).

Temas de direito urbano-ambiental. Belo Horizonte: Fórum, 2006. p. 19-50.

SANTOS, A. M.; MOTTA, A. Desafios para a sustentabilidade no espaço urbano brasileiro. In: GRAZIA, Grazia de et al. O desafio da sustentabilidade urbana. Rio de Janeiro: Projeto Sustentável: FASE, 2001. p. 83-111.

UNIVERSIDADE FEDERAL DO PARÁ (UFPA). Comissão de Regularização Fundiária. Caderno metodológico. Belém: UFPA, 2013.

VÁZQUEZ, Daniel; DELAPLACE, Domitille. Políticas públicas na perspectiva de direitos humanos: um campo em construção. SUR Revista Internacional de Direitos Humanos, São Paulo, Conectas, v. 8, n. 14, p. 35-65, jun. 2011.

Recebido em: 06/08/2015

Aprovado em: 25/02/2016 